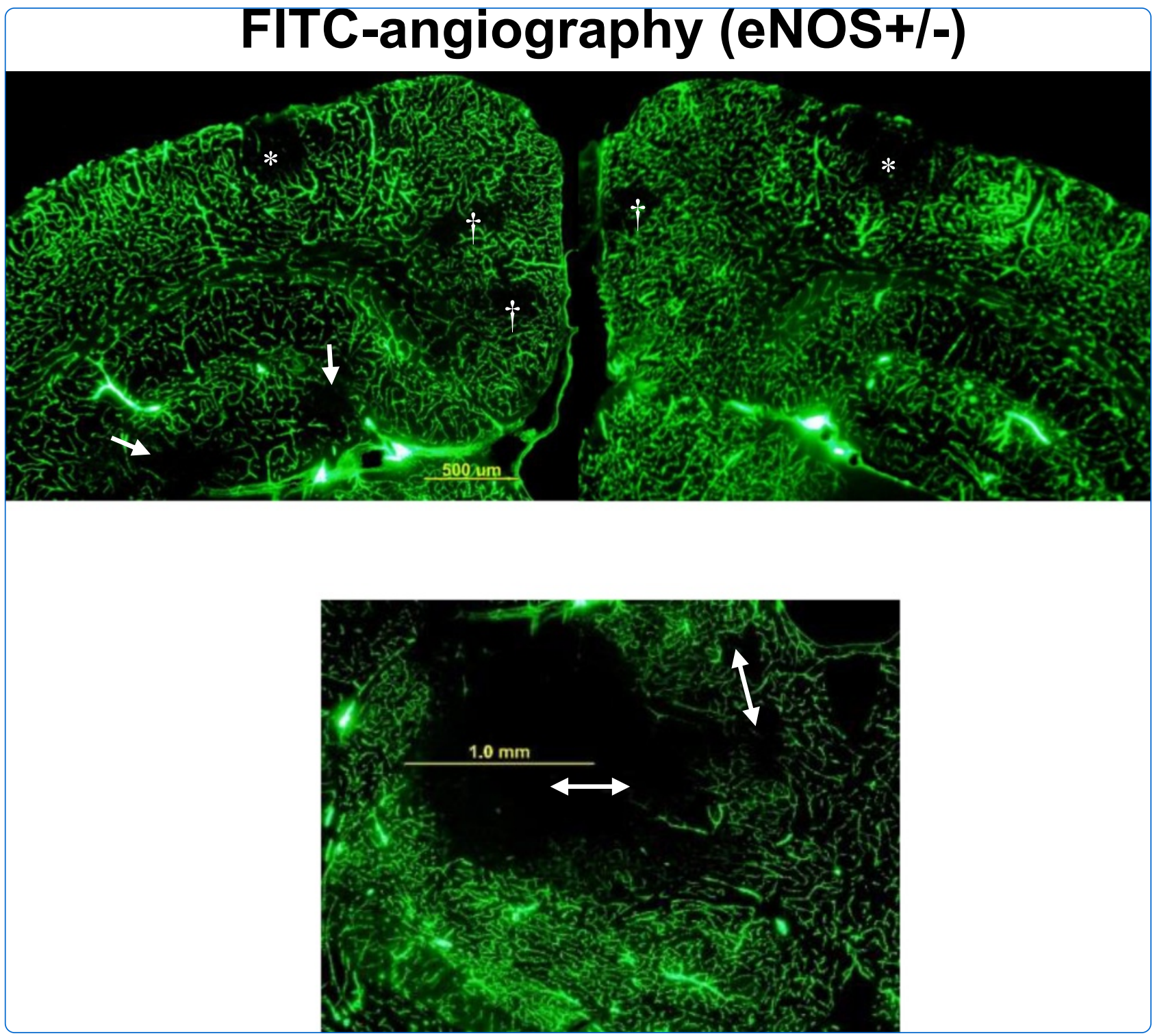

Partial eNOS deficiency causes spontaneous thrombotic cerebral infarction, amyloid angiopathy and cognitive impairment

Tan et al. 
Open Access

\title{
Partial eNOS deficiency causes spontaneous thrombotic cerebral infarction, amyloid angiopathy and cognitive impairment
}

Xing-Lin Tan ${ }^{1 \dagger}$, Yue-Qiang Xue ${ }^{1 \dagger}$, Tao Ma ${ }^{1,4}$, Xiaofang Wang ${ }^{1,5}$, Jing Jing Li ${ }^{1}$, Lubin Lan ${ }^{1}$, Kafait U. Malik', Michael P. McDonald ${ }^{2,3}$, Alejandro M. Dopico ${ }^{1}$ and Francesca-Fang Liao ${ }^{1 *}$

\begin{abstract}
Background: Cerebral infarction due to thrombosis leads to the most common type of stroke and a likely cause of age-related cognitive decline and dementia. Endothelial nitric oxide synthase (eNOS) generates NO, which plays a crucial role in maintaining vascular function and exerting an antithrombotic action. Reduced eNOS expression and eNOS polymorphisms have been associated with stroke and Alzheimer's disease (AD), the most common type of dementia associated with neurovascular dysfunction. However, direct proof of such association is lacking. Since there are no reports of complete eNOS deficiency in humans, we used heterozygous eNOS ${ }^{+-}$mice to mimic partial deficiency of eNOS, and determine its impact on cerebrovascular pathology and perfusion of cerebral vessels.
\end{abstract}

Results: Combining cerebral angiography with immunohistochemistry, we found thrombotic cerebral infarctions in eNOS ${ }^{+/-}$mice as early as 3-6 months of age but not in eNOS ${ }^{+/+}$mice at any age. Remarkably, vascular occlusions in $\mathrm{eNOS}^{+/-}$mice were found almost exclusively in three areas: temporoparietal and retrosplenial granular cortexes, and hippocampus this distribution precisely matching the hypoperfused areas identified in preclinical AD patients. Moreover, progressive cerebral amyloid angiopaphy (CAA), blood brain barrier (BBB) breakdown, and cognitive impairment were also detected in aged $\mathrm{eNOS}^{+-}$mice.

Conclusions: These data provide for the first time the evidence that partial eNOS deficiency results in spontaneous thrombotic cerebral infarctions that increase with age, leading to progressive CAA and cognitive impairments. We thus conclude that $\mathrm{NNOS}^{+/-}$mouse may represent an ideal model of ischemic stroke to address early and progressive damage in spontaneously-evolving chronic cerebral ischemia and thus, study vascular mechanisms contributing to vascular dementia and AD.

Keywords: Endothelial nitric oxide synthase (eNOS), Cerebral chronic hypoperfusion, Cerebral dysfunction, Thrombosis, Microvessel occlusion, Cerebral microinfarction, Vascular dementia, Cerebral amyloid angiopathy (CAA)

\section{Background}

Nitric oxide (NO) synthesized in endothelial cells from $\mathrm{L}$-arginine by endothelial nitric oxide synthase (eNOS) is the major source of $\mathrm{NO}$ in brain vessels and an important signaling molecule in vasculogenesis [1-3], cerebral blood flow regulation $[3,4]$, atherosclerosis and thrombosis [5-8], and amyloid-beta $(A \beta)$ production [9-12]. Thus, intact endothelial function via NO confers key homeostatic

\footnotetext{
* Correspondence: fliao@uthsc.edu

${ }^{\dagger}$ Equal contributors

'Departments of Pharmacology, University of Tennessee Health Science

Center, 874 Union Avenue/Crowe 401, Memphis, TN 38163, USA

Full list of author information is available at the end of the article
}

balance in normal brain physiology, which raises the possibility that endothelial dysfunction associated with deficiency of eNOS and endothelial NO causes cerebrovascular pathology and neurological disease. Indeed, eNOS gene polymorphisms have been reported to be associated with carotid atherosclerosis [13], ischemic heart and brain [14-16] and possibly, with Alzheimer's disease (AD) [17]. Correlations between eNOS polymorphisms and decreased NO bioavailability or endothelial dysfunction have also been reported [13, 18, 19], and

\section{Biomed Central}

(c) 2015 Tan et al. This is an Open Access article distributed under the terms of the Creative Commons Attribution License (http://creativecommons.org/licenses/by/4.0), which permits unrestricted use, distribution, and reproduction in any medium, provided the original work is properly credited. The Creative Commons Public Domain Dedication waiver (http:// creativecommons.org/publicdomain/zero/1.0/) applies to the data made available in this article, unless otherwise stated. 
reduced eNOS expression has been recently found in AD brain [20].

The importance of eNOS in the cardiovascular system was demonstrated in animal models [21]. Targeted deletion of eNOS was shown to cause spontaneous hypertension and exacerbate stroke outcome [3, 4, 21, 22]. In addition, multiple hematologic abnormalities [5, 7], cerebral arteriolar hypertrophy [4], renal thrombotic microangiopathy $[8]$ and myocardial infarction $[2,6]$ have all been reported in eNOS-deficient mice. Remarkably, neither spontaneously evolving microinfactions nor gross anatomical/ histological changes in brain vasculature were observed in these mice $[4,22]$. eNOS polymorphisms and haplotypes, however, have been reportedly associated with increased risk of cerebral small-vessel disease as well as silent brain infarction in humans $[14,15]$. It should be underscored that the vast majority of work revealing pivotal roles of eNOS in pathophysiology has been conducted on young $\mathrm{eNOS}^{-/-}$mice.

Remarkably, there are no reports of complete eNOS deficiency in humans, caution should be taken when extrapolating conclusions to humans based on data obtained in $\mathrm{eNOS}^{-/-}$mice. Heterozygous $\mathrm{eNOS}^{+/-}$mice, however, constitute an ideal model to begin to explore a possible role of partial eNOS deficiency in neurovascular pathology. Moreover, since aging is an important risk factor for cerebrovascular dysfunction and AD [23-26], it remains critical to determine whether aged $\mathrm{eNOS}^{+-}$ mice present histological and/or functional deficits that may be conclusive to stroke and AD. To address these questions, we combined immunohistochemistry with cerebral fluorescein isothiocyanate (FITC)-dextran microangiography and thus identify potential changes in both brain tissue and vessels in aged (18 months) and young (6 months) $\mathrm{eNOS}^{+/-}$when compared with littermate $\mathrm{eNOS}^{+/+}$mice.

\section{Results}

eNOS expression, blood pressure, and cerebral microvessel density

Consistent with previous reports [4, 22], both young (6 months) and aged (18 months) $\mathrm{eNOS}^{+/-}$mice had lower levels of eNOS protein in brain tissue and a normal range of blood pressure (Fig. 1a and b, respectively). Interestingly, immunohistochemistry showed a higher microvessel density in hippocampus but not in cerebral neocortex in aged $\mathrm{eNOS}^{+/-}$mice when compared with their littermate wild-type $\left(\mathrm{eNOS}^{+/+}\right.$) or young $\mathrm{eNOS}^{+/-}$mice (Additional file 1: Figure S1).

\section{Spontaneous cerebral thrombosis and microinfarctions}

To evaluate the functionality of the hyperplasic vessels found in the aged eNOS ${ }^{+/}$mice, cerebral fluorescent angiography was performed, which confirmed the immunohistochemical findings of increased microvascular density in hippocampus. Remarkably, angiography revealed multiple cortical/subcortical nonperfusion areas in both young and aged $\mathrm{eNOS}^{+/-}$mice which were not found in littermate $\mathrm{eNOS}^{+/+}$(Fig. 2a, b). Moreover, the nonperfusion areas were more frequent in aged than in young $\mathrm{eNOS}^{+/-}$mice (Fig. 2c). It must be underscored that we did not observe nonperfusion areas in $\mathrm{eNOS}^{+/+}$mice up to 24 months of age. Strikingly, most nonperfusion lesions in aged $\mathrm{eNOS}^{+/-}$ mice were bilateral (Fig. 2b). These lesions were not uniformly located throughout the brain but primarily restricted to rather defined areas (in frequency order): parietal association, temporal association and retrosplenial granular cortexes, hippocampus and thalamus.

In addition, we observed markedly higher FITC signal in the microvessels surrounding the larger nonperfusion areas (Fig. 2d), suggesting a compensatory vascular dilation presumably due to more severe ischemia in these older animals than in younger mice. While most


Fig. 1 a Reduced eNOS protein expression in heterozygous mice. eNOS immunoblotting of $20 \mu \mathrm{g}$ of total brain lysates. ${ }^{* *} P<0.01$. $n=4$ animals of each genotype. Bars represent mean \pm s.e.m. b Mean arterial pressure (MAP) were calculated based on the measured systolic (SBP), diastolic (DBP). eNOS ${ }^{+/}$mice have a propensity to develop hypertension but blood pressure is within normal range compared to age-matched wild-type eNOS $^{+/+}$mice. $P=0.02$ by Student's $t$-test. $n=10$ animals of each genotype. Bars represent mean \pm s.e.m 


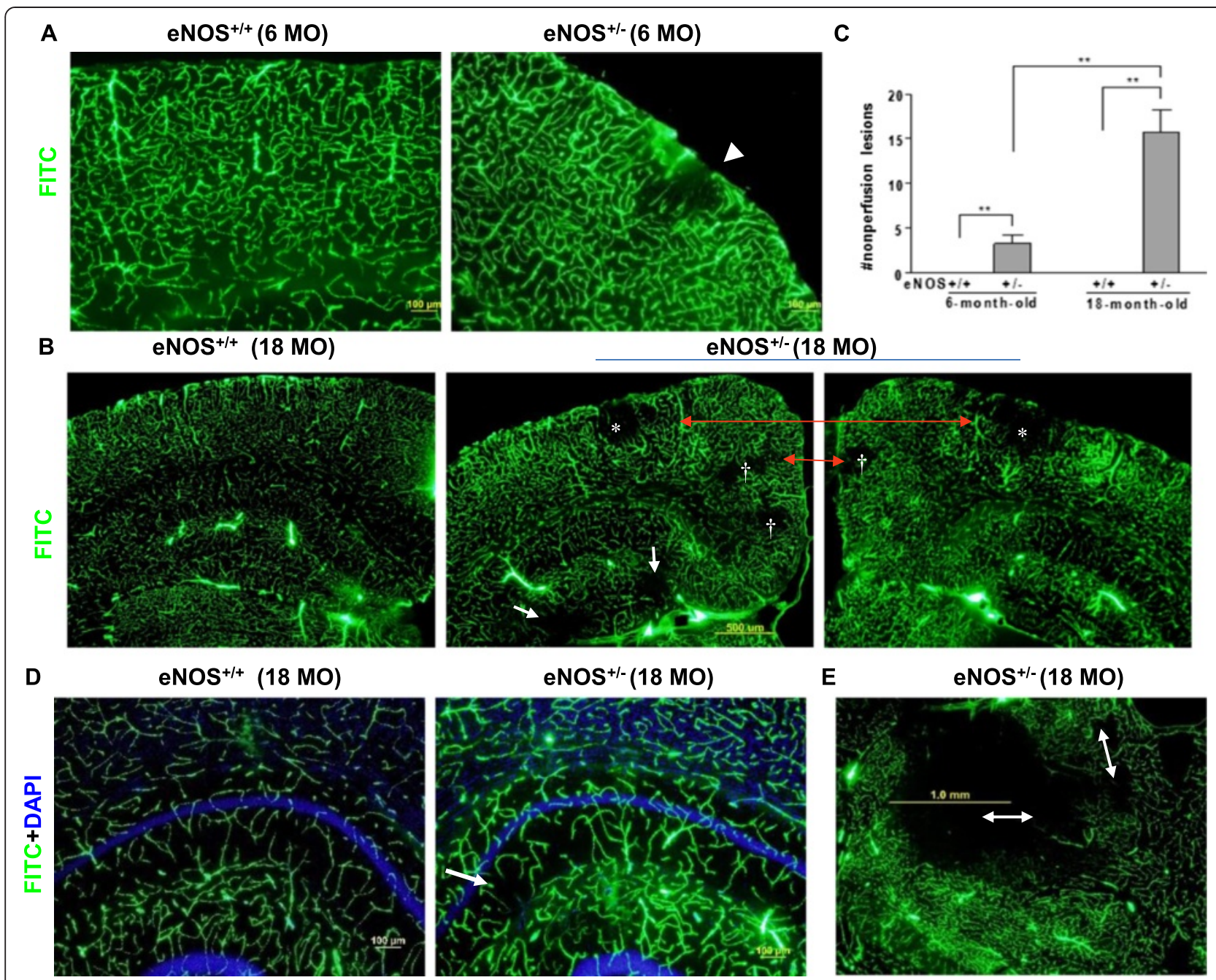

Fig. 2 Multiple cerebral occluded lesions in eNOS ${ }^{+/-}$mice. a, b Representative FITC-dextran angiographic micrographs in young (a) and aged eNOS mice (b). Arrows indicate infarctions in hippocampus; red double arrows, bilateral lesions; asterisks, parietal association cortex; daggers, retrosplenial granular cortex; arrowheads, temporal association/temporoparietal cortexes. Scale bars: $100 \mu \mathrm{m}$ (a) and $500 \mu \mathrm{m}$ (b). c Quantification of the number of cerebral nonperfusion lesions/infarctions per mouse. ${ }^{* *} P<0.0005 . n=4-6$ mice each genotype. Bars represent mean \pm s.e.m. d Representative FITC-dextran angiographic micrographs with DAPI counterstaining. Scale bars: $100 \mu \mathrm{m}$. White arrow indicates a nonperfusion lesion. e Representative angiograph shows multiple cerebral occluded lesions in thalamus (double arrows). Scale bar: 1 mm

nonperfusion lesions were small (diameter of 100$500 \mu \mathrm{m})$ and the cortical lesions rarely extended beyond the outer half of cortex, some thalamic lesions were up to $1.5 \mathrm{~mm}$ in diameter (Fig. 2e). Interestingly, these nonperfusion lesions were rarely found in sections without hippocampal involvement (i.e., the anterior portion of the brain), underscoring the particular vulnerability of hippocampal formation and function to partial eNOS deficiency.

To determine whether nonperfusion areas were due to vessel obstruction or an actual loss of blood vessels, we combined cerebral fluorescent angiography with immunofluorescent staining using CD31 and GluT1. Owing to thick brain sections (100 um) from FITC-dextran perfused brains, immunostaining signals were much weaker (Fig. 3a and b) as compared to formalin-fixed tissue sections $(40 \mu \mathrm{m})$. To our surprise, CD31-positive vessels with diameters of 5-20 $\mu \mathrm{m}$ were largely present within nonperfusion areas (Fig. 3b, c), suggesting that vessel loss does not critically contribute to the nonperfused areas found in $\mathrm{eNOS}^{+/-}$mice. This was confirmed by another vascular marker GluT1 (Fig. 3d), though displaying a discontinued profile. These findings are consistent with the fact that microvessel density remains unchanged in neocortex in aged $\mathrm{eNOS}^{+/-}$mice.

In coronal sections, $\mathrm{H}$ \& $\mathrm{E}$ staining revealed markedly reduced cellularity and necrosis in the core of lesion in $\mathrm{eNOS}^{+/-}$mice (12 months) (Fig. 4a), despite marked gliosis (GFAP/astroglias and Iba-1/microglias) (Fig. 4b). The nonperfusion areas detected in $\mathrm{eNOS}^{+/-}$brains followed 




all criteria required by the accepted definition of microinfarcts: sharply delineated microscopic regions of cellular death or tissue necrosis, sometimes with cavitation [27]. Moreover, different stages of microinfarcts based on the $\mathrm{H}$ \& $\mathrm{E}$ histology were detected in $\mathrm{eNOS}^{+/-}$brain at various ages; the multiple pale lesions detected in older mice most likely revealed chronic lesions of late staged infarcts, presumably with the damaged tissue phagocytized (Fig. 4a, right panel). No similar lesions at any stage were detected in $\mathrm{eNOS}^{+/+}$mice at all ages.

Next, to elucidate the cause(s) of vascular obstruction, we determined the presence of intravascular thrombus. Immunohistochemistry of fibrinogen/fibrin confirmed multiple cortical and subcortical intravascular microthrombi blocking the vessels in aged $\mathrm{eNOS}^{+/-}$mice (Fig. 4c) and, to a lesser degree, in young $\mathrm{eNOS}^{+/-}$mice. In sharp contrast, microthrombi were never detected in either aged or young $\mathrm{eNOS}^{+/+}$mice (data not shown). Some intravascular thrombi were much smaller than the lumen of the arterioles, but they were not washed out by transcardial perfusion during tissue preparation (Fig. 4c, right lower panels), indicating that these in situ mural thrombi were due to thrombosis rather than thromboembolism. The presence of continuous strings of fibrinogen-positive signal along the vessels also supports the occurrence of thrombosis.
CAA, blood brain barrier (BBB) breakdown, and cognitive dysfunction

We and others have found BACE1 upregulation and elevated levels of soluble $\mathrm{A} \beta$ in young adult $\mathrm{eNOS}^{-/-}$brain (4 months) [9-12]. We then sought to determine amyloid deposition in older mice. In aged $\mathrm{eNOS}^{+/-}$mice, we found significant cerebral amyloid angiopathy (CAA) that showed dense $A \beta$ deposits within and surrounding the vessel walls of the arterioles in cerebral pia mater and parenchyma (Fig. 5a-c) as well as in the hippocampi (Fig. 5d). CAA was also found in the capillaries reaching the temporoparietal cortex, hippocampal formation, amygdala, hypothalamus, and striatum (data not shown). In contrast, CAA was only occasionally found in aged $\mathrm{eNOS}^{+/+}$. Moreover, while young $\mathrm{eNOS}^{+/-}$mice ( 8 months) displayed mild CAA, no evidence of CAA could be found in young $\mathrm{eNOS}^{+/+}$mice (data not shown). Detection of $\mathrm{A} \beta$ aggregation by Thioflavine $\mathrm{S}$ staining only revealed a diffusive signal in the brains of $\mathrm{eNOS}^{+/-}$mice, rather than as focal plaques as in 5XFAD mice (Fig. 5e). Quantification of $\mathrm{A} \beta$ immunoreactivity by ELISA in forebrain indicated a two-fold increase in soluble A $\beta 40$ starting from young aged $\mathrm{eNOS}^{+/-}$mice (4-6 months) when compared to littermate controls (Fig. 5f).

To better understand the consequence of cerebral thrombosis and CAA, we next studied the leakage of 


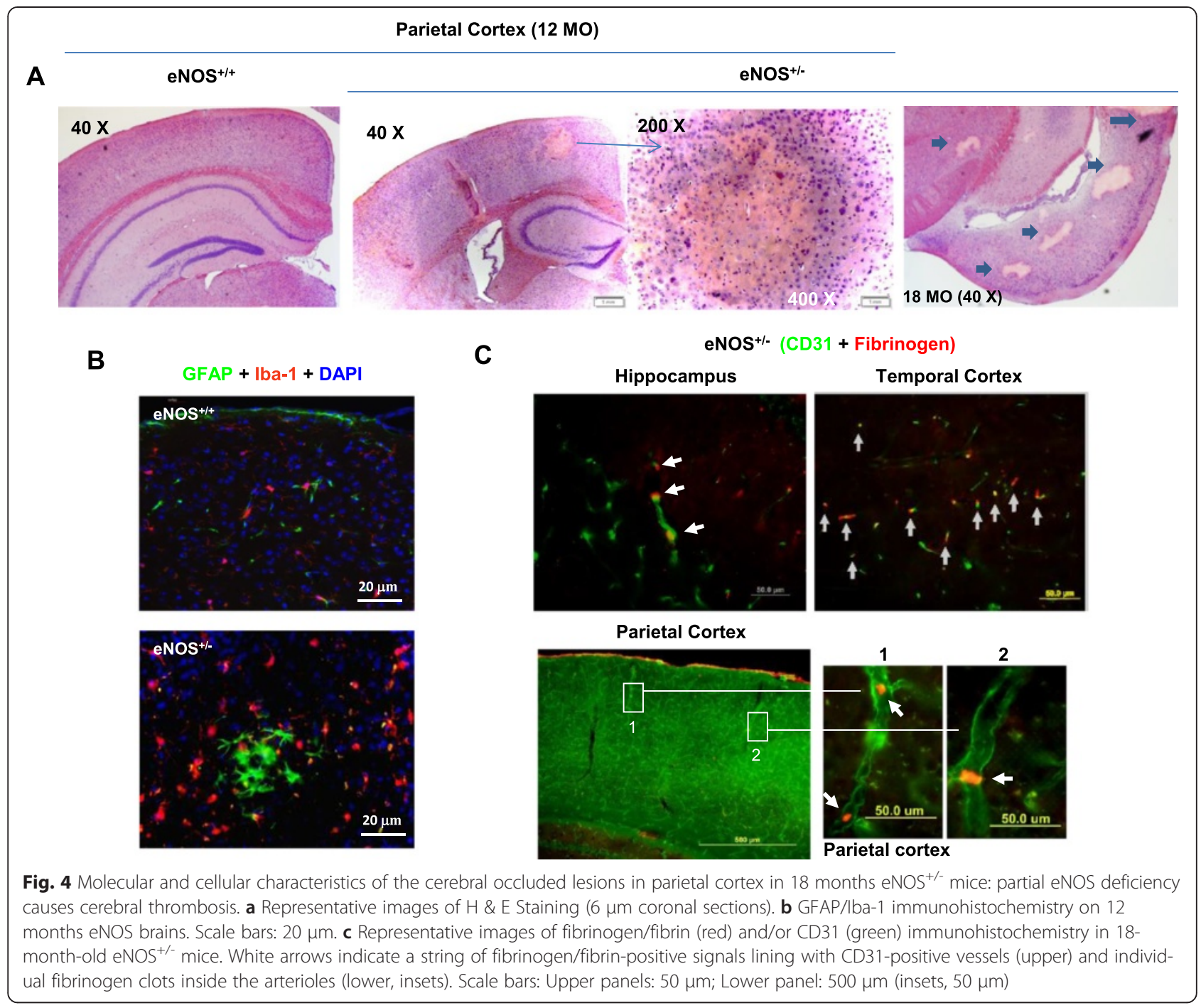

endogenous blood-derived protein in the brain. As shown in the cortex, aged $\mathrm{eNOS}^{+/-}$mice had localized extravasations of FITC-dextran $(150 \mathrm{Kd}$, Fig. 6a, right panel) and serum IgG (Fig. 6b, c, Additional file 1: Figure S2). Locations and distribution of serum IgG extravasation were well matched with those of nonperfusion areas as demonstrated by angiography in aged $\mathrm{eNOS}^{+/-}$mice, consistent with the notion that thrombotic cerebral infarctions and localized BBB breakdown are pathophysiologically related in the $\mathrm{eNOS}^{+/-}$mouse. Moreover, vascular smooth muscle cell degeneration (Fig. 6d) and a greater number of cerebral microhemorrhages scattered over bilateral hemispheres (Fig. 6e, f).

Cerebral thrombosis or microinfarctions likely contribute to cognitive decline. Recently, a single cortical microinfarction event induced by penetrating arteriole obstruction was shown to cause cognitive deficits in mice [28]. We therefore hypothesized that eNOS partial deficiencyinduced cerebral infarctions have a negative impact on cognitive performance. Consistent with this idea, by water maze test, we found progressive cognitive deficits in old $\mathrm{eNOS}^{+/-}$mice compared to $\mathrm{eNOS}^{+/+}$controls; no significant difference found in young mice (6 months) (Fig. 7a). Moreover, marked neuroinflammation (activated microglias/Iba-1 and astrocytes/GFAP) and neurodegeneration with cortical atrophy ( $\sim 20 \%$ reduction of cortical thickness) were detected in 24 months) $\mathrm{eNOS}^{+/-}$mice (Fig. 7b).

\section{Altered molecular profiles}

To determine molecular changes in $\mathrm{eNOS}^{+/}$mice, we performed qRT-PCR of frontal brain tissue. When compared with littermate controls, $\mathrm{eNOS}^{+/-}$mice showed progressive changes in genes involved in a variety of neurovascular processes such as angiogenesis, inflammation, and BBB transport. Specifically, we found a significant increase in the mRNAs of bFGF-2 and MMP2 (but not VEGF-A or MMP9 or thrombin), ICAM-1, IL-6, TNF- $\alpha$ and GFAP (but not IL-1 $\beta$ ) (Fig. 8a). Interestingly, 


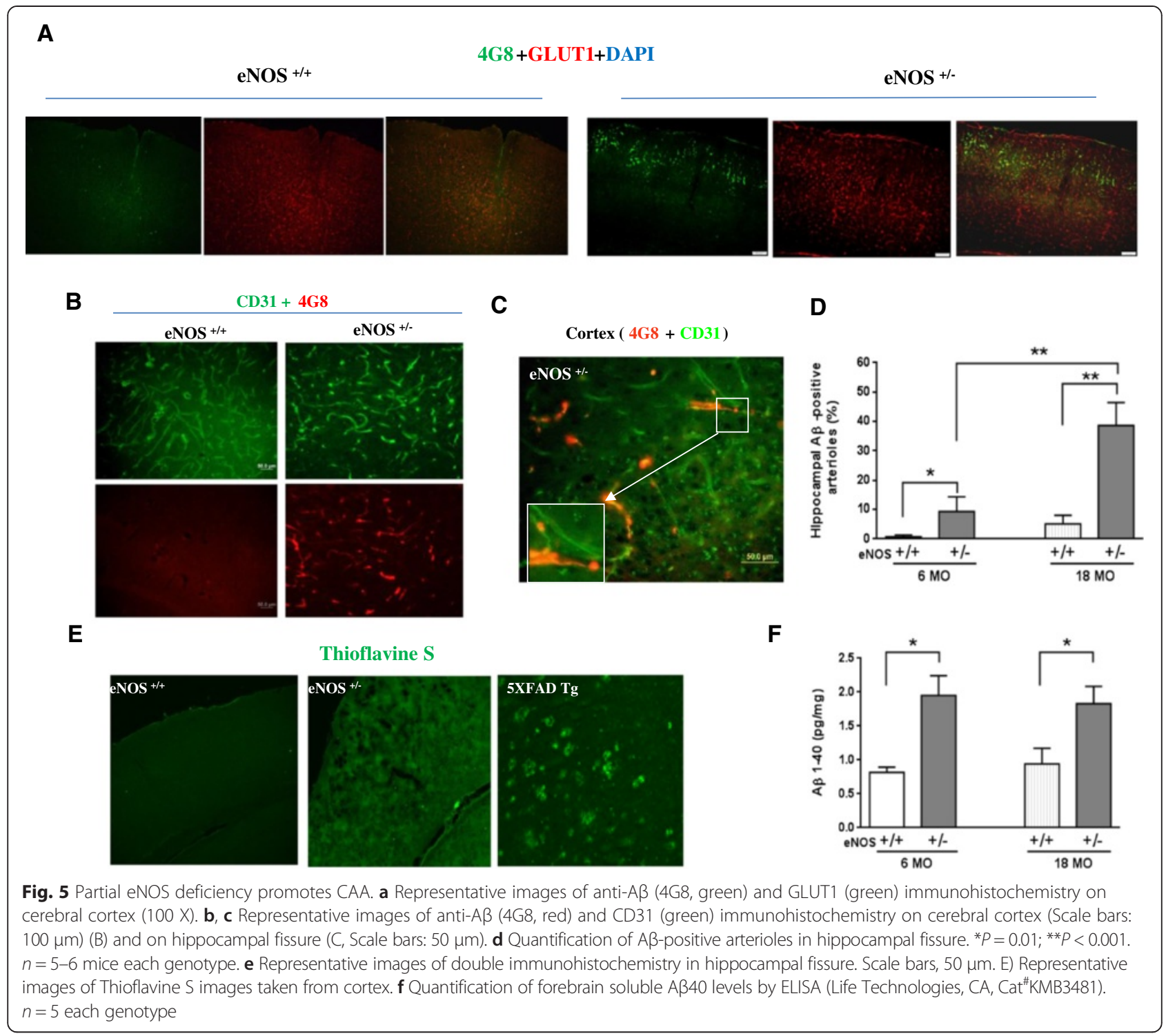

gene Ager (RAGE) is upregulated but not lrp1 (LRP1). Lipoprotein receptor-related protein (LRP-1) and receptor for advanced glycation end products (RAGE) are the two molecules most closely related to $A \beta$ uptake/clearance and protein transport across the BBB [29-32]. Altered expression of either of these capillary endothelial receptor proteins could indicate a dysfunction of the $\mathrm{BBB}$ and its transport regulation of $A \beta$. The increased expression of Abcb1b (ABCB1b, APC transporter) also strongly suggests a disrupted function in BBB transport. In addition, TGF $\beta$ has been extensively studied in terms of its role in $\mathrm{A} \beta$ biogenesis and neuroinflammation [33]. It is thus very important to study eNOS-regulated TGF $\beta$, which has thus far been unexplored. Our data show a $\sim 2$-fold increase in tgfb1 mRNAs in the eNOS ${ }^{+/}$mouse brain. This first finding suggests an involvement of TGF $\beta$-mediated pathways in eNOS mice, which warrants future investigation.
Finally, biochemical analysis also reveals evidence of increased BACE1 expression and hyperphosphorylated tau as well as CNS insulin resistance in aged $\mathrm{eNOS}^{+/-}$ mice (Fig. 8b).

\section{Discussion}

The present study reveals, for the first time, the occurrence of spontaneous cerebral thrombosis at early age in $\mathrm{eNOS}^{+/-}$mice ( $<6$ months). Moreover, these thrombotic phenomena increase with age, and are accompanied by progressive CAA detectable from 8 months of age and cognitive dysfunction detected at old age (18 months). But, perhaps what is most striking is that we detected multiple occluded areas/lesions with diameters ranging from 0.1 to $1.5 \mathrm{~mm}$ in three primary areas (i.e., temporoparietal and retrosplenial granular cortexes as well as hippocampus). Each of these regions matches precisely 


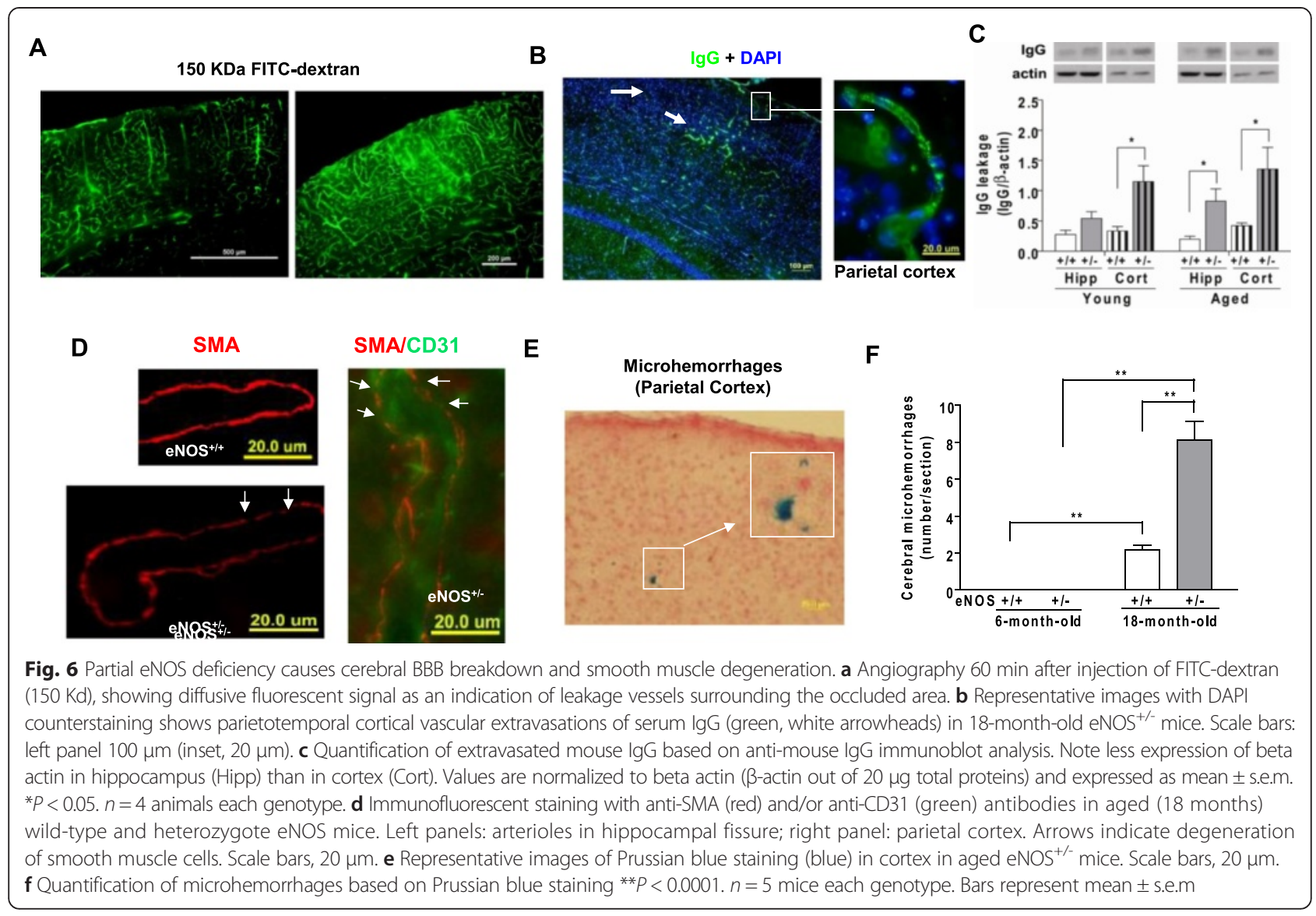

to the hypoperfused areas identified in pre-clinical AD patients [34-36], which indicates that the partial eNOS-deficient mice is a spontaneous model of chronic hypoperfusion.

Microscopic examination of aging brain sections, particularly those exhibiting cognitive decline, often reveal numerous microinfarctions resulting from small vessel pathologies such as arteriolosclerosis or CAA [27]. Microinfarctions and ischemic stroke can be induced by thrombosis, which are usually associated with increased cellularity due to inflammatory infiltration and gliosis during an acute stage. We observed reduced cellularity in the cores of occluded lesions most of time. Based on the neuropathological definition of sharply delineated microscopic regions of cellular death or tissue necrosis, we believe the occluded lesions are in fact microinfarctions. The pale regions (Fig. 4a, right panel) likely represent chronic lesions (i.e., "old infarcts"), which typically demonstrate cavitation with surrounding fibrillary gliosis. We occasionally detected more freshly looking lesions in the neocortex, which showed an acute ischemic appearance of red neurons and loss of colorful staining quality (not shown). Given the high frequency and widespread distribution pattern in eNOS mice, these microinfarctions predictably contribute to direct disruption of important cognitive networks.

While these results were fascinating, an important question remains unanswered: what causes cerebral thrombosis (and or thrombotic microinfarctions) if there was no detection of significant changes in the blood pressures of $\mathrm{eNOS}^{+/-}$mice at all ages. We favor the hypothesis that chronic partial eNOS deficiency causes endothelial and platelet dysfunction, which leads to thrombotic cerebral infarctions. Indeed, vascular and platelet activity have been found to be compromised in eNOS-deficient mice [37].

Based on our data on the sequential events of thrombosis, CAA and cognitive decline in $\mathrm{eNOS}^{+/-}$mice, we further propose the following theory: that chronic partial eNOS deficiency causes endothelial and platelet dysfunction that ultimately leads to the thrombotic cerebral infarctions and associated BBB breakdown that facilitate $\mathrm{A} \beta$ production and impair $\mathrm{A} \beta$ clearance [38]. Both of these events promote vascular deposition of $A \beta$, resulting in vessel tortuosity (Additional file 1: Figure S3) which in turn triggers platelet activation and exacerbates thrombotic cerebral infarction [39]. Although we did not measure the nitric oxide (NO) content in the brain of $\mathrm{eNOS}^{+/-}$mice, reduced levels of systemic NO in all 
A

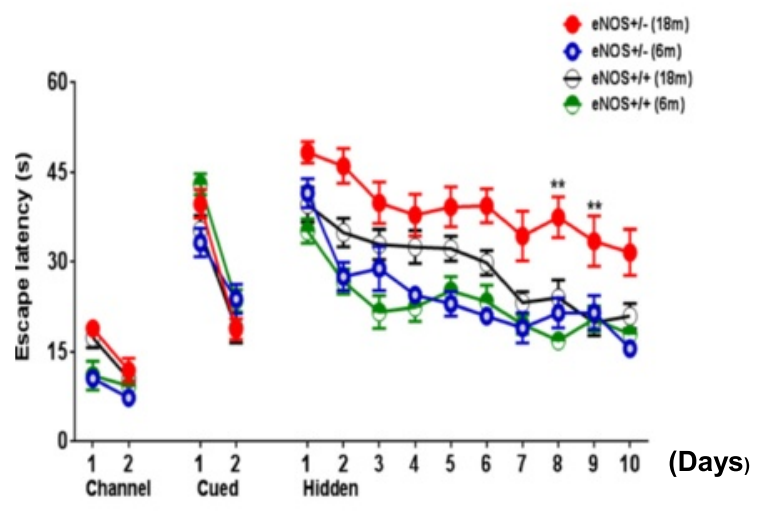

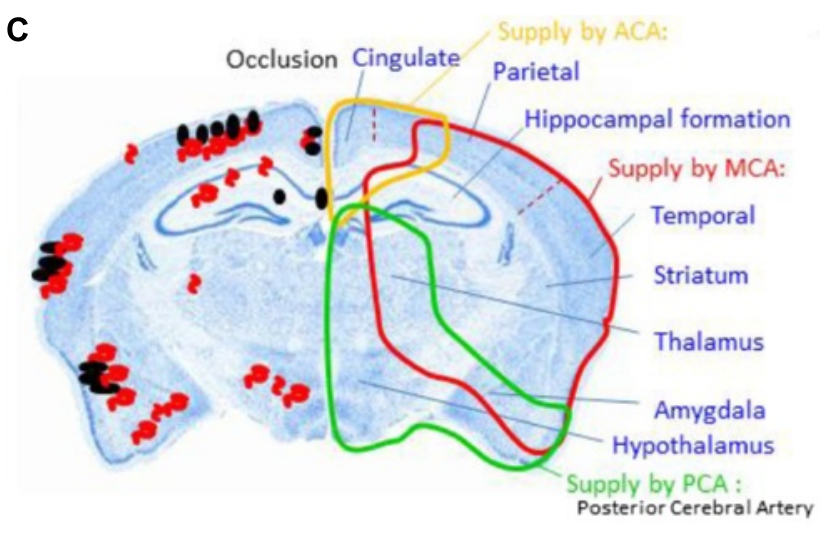

C

(24MO)

B
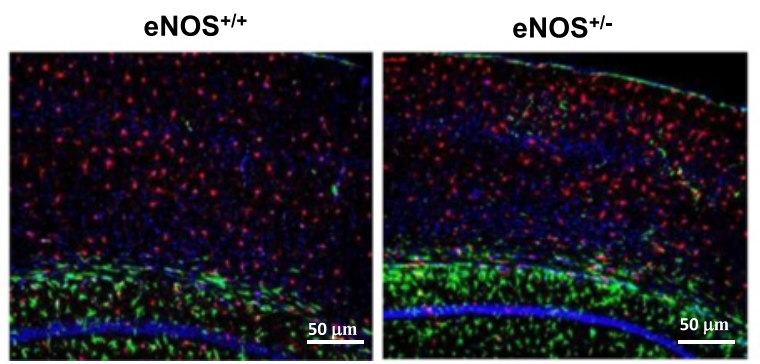

$\mathrm{eNOS}^{+/+}$

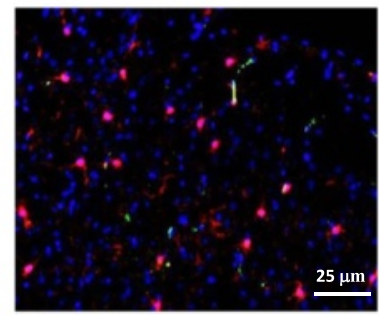

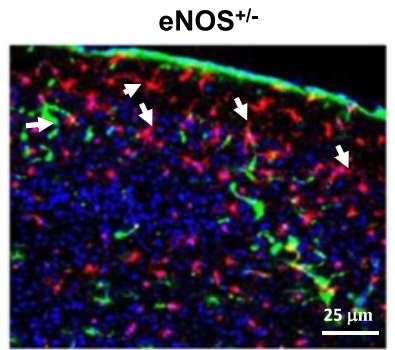

Fig. 7 a Cognitive functions in heterozygous eNOS knockout (eNOS ${ }^{+/}$) mice. Spatial learning and memory evaluated by water maze tests reveals no significant differences between young (6-month-old) eNOS ${ }^{+/-}$mice and their littermate wild-type $\left(\right.$eNOS $\left.{ }^{+/+}\right)$mice $(n=10$ each genotype), but severe impairment in aged $\mathrm{NOS}^{+/-}$mice when compared to eNOS ${ }^{+/+}$mice $\left(n=18\right.$ each). Data are presented as means \pm SEM. ${ }^{* *} P<0.005$ when $\mathrm{NNOS}^{+/-} 18$ months group was compared to that of the littermate eNOS ${ }^{+/}$mice. $\mathbf{b}$ Representative images of GFAP and Iba-1 double immunohistochemistry. White arrowheads indicate activated microglias. Scale bars: $50 \mu \mathrm{m}$ form the left panels and $25 \mu \mathrm{m}$ for the right panels. c Schematic summary of the relative locations of the identified occluded lesions (black) and CAA (red) in old eNOS ${ }^{+/-}$mice

organs were determined based on dose-dependent phenotypes detected in these mice as compared to $\mathrm{eNOS}^{+/+}$ and $\mathrm{eNOS}^{-/-}$littermates [40-44], with one exception [45]. Thus, it is generally believed that the phenotypes observed in eNOS-deficient mice are due to the reduced NO levels/functions.

It should be noted that our report is the first to use a mouse model that does not overexpress a mutant amyloid precursor protein (APP) or presenilin (PS1) gene to develop aberrant $A \beta$ generation and deposition within vessel walls (presumably via an eNOS-dependent regulatory mechanism). Moreover, contrary to most FAD models, including a recently established APP-PS1 knock-in model [46], in which amyloid pathology (CAA in particular) causes cerebral hypoperfusion, our model clearly demonstrates that chronic hypoperfusion in fact can induce CAA. The other major differences in our spontaneous eNOS and FAD models are the degree of CAA and the composition of mouse versus human $A \beta$ species. The two-fold increase of $A \beta$ observed in both soluble and diffusive plaques in eNOS mice probably indicate milder CAA when comparing to other FAD models (Fig. 5) [47]. However, we did not observe focal $\mathrm{A} \beta$ plaques at 24 months of age in $\mathrm{eNOS}^{+/-}$mice, which is consistent with the notion that endogenous mouse $A \beta$ is less aggregable and do not form plaques. Nevertheless, it may be informative to further compare our eNOS model with those of FAD's. Since mouse $A \beta$ is less toxic than human's, it may also be important to cross eNOSdeficient mice with AD mice expressing human FAD APP mutants to study interplay between chronic hypoperfusion and amyloid progression.

Cerebral hypoperfusion has been identified as a hallmark in the pre-clinical phase of $\mathrm{AD}$, although whether it plays a causal role in $A D$ pathogenesis remains unclear. Cerebral Hypoperfusion and CAA are both invariant features of dementia and $\mathrm{AD}[48,49]$. Thus we propose that cerebral hypoperfusion/infarction and CAA form a vicious cycle for vascular dysfunction and, ultimately, dementia (Fig. 9). This hypothesis is supported by the anatomically close vicinity of these two events (Fig. 7a), as well as by the notion that severe CAA is induced by cerebral cortical microinfarctions in humans [50]. Given that FAD mutations were only detected in $<2 \%$ of $\mathrm{AD}$ cases, and hypoperfusion was identified in a majority of preclinical $\mathrm{AD}$ patients 


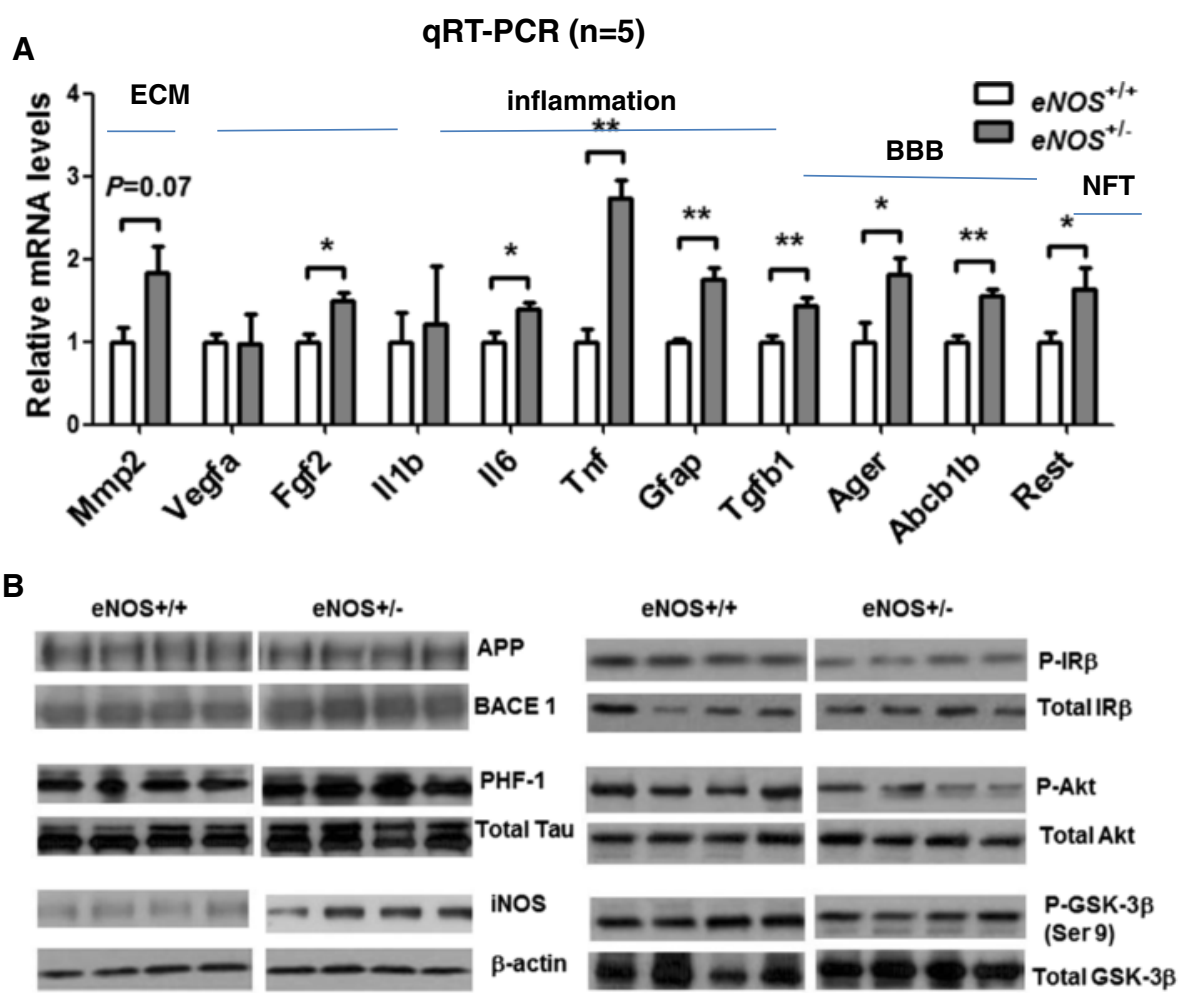

Fig. 8 Molecular evidence of neuroinflammation and impaired insulin resistance and BBB transport. a Quantitative qRT-PCR of frontal brain tissue. b Western blot of frontal brain lysates $(20 \mu \mathrm{g})$. Gene names used are Mmp2: MMP2; Vegfa: VEGFa; Fgf2: FGF2; II1 b: IL-1 $\beta$; Tnf: TNF-1a; Gfap: GFAP; Tgfb1: TGF-1ß; Ager: RAGE; Abcb1b: ABCB1B; Rest: REST

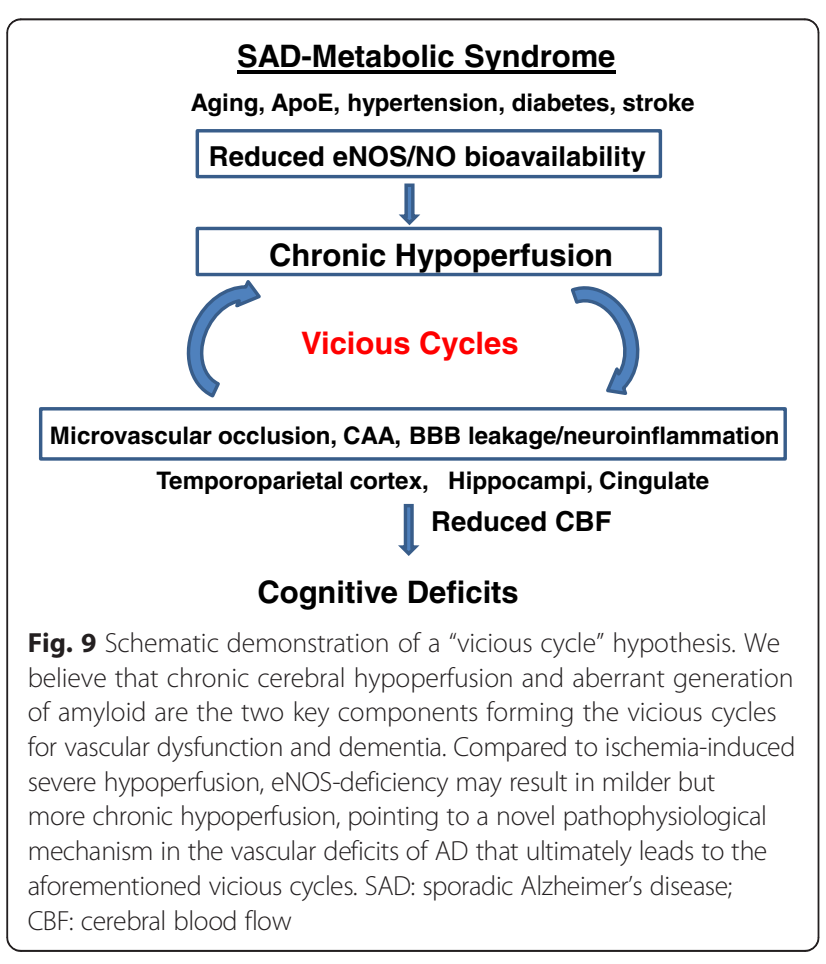

without detectable amyloid pathology, an $\mathrm{eNOS}^{+/-}$ model is more representative of sporadic AD cases and is predictably useful for studying early pathogenic mechanisms. Compared to ischemia-induced severe hypoperfusion, eNOS-deficiency may result in milder but more chronic hypoperfusion, suggesting a novel pathophysiological mechanism in the vascular deficits of $A D$ that ultimately leads to the aforementioned vicious cycle.

\section{Conclusions}

Stroke is the third leading cause of death and an important cause of age-related cognitive decline and dementia. However, the development of effective therapies for stroke and vascular dementia has been limited due to the lack of suitable animal models [51]. The only non-induced model that mimics both microvessel and parenchymal changes in human stroke is the spontaneously hypertensive strokeprone rat. Although some susceptibility genes have been identified [52], this rat line is highly inbred and may be of limited relevance [53]. Consistent with the previous report [22], our data reveal an absence of severe hypertension in eNOS-deficient mice, yet interestingly enough these mice spontaneously develop cerebral infarctions. Therefore, the $\mathrm{eNOS}^{+/-}$mouse may represent a spontaneous cerebral infarction model for stroke and vascular dementia, best fit 
to understand pathophysiological mechanisms that would assist in developing novel preventative therapeutic strategies. Stroke is an important risk factor for AD [24-26]. Our most striking finding is that partial eNOS deficiencyinduced cerebral infarctions match well with the patterns of cerebral blood flow distribution in AD patients [34-36]. This suggests that the eNOS deficient mouse may also represent a model for sporadic $\mathrm{AD}$, which would greatly improve our understanding of AD etiology and ultimately create better prevention and treatment therapies.

\section{Methods}

Materials and methods

Animals

$\mathrm{eNOS}^{+/-}$and littermate $\mathrm{eNOS}^{+/+}$mice were derived from interbreeding $\mathrm{eNOS}^{+/-}$and $\mathrm{eNOS}^{+/+}$mice by using $\mathrm{eNOS}^{-1-}$ mice $\left(\mathrm{NOS}^{\mathrm{tm} 1 \mathrm{Unc}} / \mathrm{J}\right.$ Jackson Laboratory, Bar Harbor ME). Each mouse was genotyped.

\section{Cerebral fluorescent angiography and tissue collection}

Cerebral fluorescent angiography was performed as described in detail elsewhere [54]. Briefly, FITC-dextran (2000 Kda; $0.1 \mathrm{~mL} 50 \mathrm{mg} / \mathrm{mL}$ in double-distilled water; Sigma, St. Louis, MO, USA) was administered intravenously via mouse tail vein. FITC-dextran remained dissolved and free in plasma. Two minutes after injecting FITC-dextran, animals were sacrificed. Brains were rapidly removed and placed in $4 \%$ paraformaldehyde (PFA) in PBS at $4{ }^{\circ} \mathrm{C}$ for $24 \mathrm{~h}$ and then incubated in $30 \%$ sucrose in PBS for another $24-36 \mathrm{~h}$ at $4{ }^{\circ} \mathrm{C}$. Sequential coronal sections $(100 \mu \mathrm{m}$ thick) were cut using a vibratome and kept at $-20{ }^{\circ} \mathrm{C}$ in an antifreeze solution (ethylene glycol: glycerol: 0.1 M PBS: double-distilled water $=1: 1: 1: 1)$ until further processing. For the permeability test, we injected FITC-dextran (150 Kda; $0.1 \mathrm{~mL}$ $50 \mathrm{mg} / \mathrm{mL}$ ) via tail vein and perfused mice $60 \mathrm{~min}$ after injection before processing for vibratome sections.

\section{Measurement of blood pressure}

Systolic (SBP), diastolic (DBP) and mean arterial pressure (MAP) were measured using a noninvasive tail-cuff method (model XBP 1000, Kent Scientific, Torrington, CT) as described [55]. All measurements were taken in the morning, and the first 5 of 25 measurements taken each day was discarded to obtain data after the mouse was acclimatized to the equipment. Blood pressure was measured for 4 consecutive days, and mean values from individual mice were used for analysis.

\section{Morris Water Maze Test (MWM)}

Spatial learning and memory were examined in a MWM task as we previously described in detail [56]. A video camera was mounted at the height of $180 \mathrm{~cm}$ above the center of the maze, and all data were recorded with a computerized video system. Escape latency (finding the submerged escape platform) and path length to find the hidden platform were recorded. On day 9, the probe test was performed by removing the platform and allowing each mouse to swim freely for $60 \mathrm{~s}$. The total length of the swim path during the testing period was recorded. The time that mice spent swimming in the target quadrant (where the platform was located during hidden platform training) was measured. For the probe trials, the number of times the mice crossed where the platform had been located was also measured and calculated.

\section{Histocytochemistry}

Mice were perfused transcardially with ice-cold PBS followed by ice-cold $4 \%$ PFA in PBS. Then, brains were removed from the cranium. After postfixation in $4 \%$ PFA in PBS at $4{ }^{\circ} \mathrm{C}$ overnight, brains were incubated in $30 \%$ sucrose in PBS for $24-36 \mathrm{~h}$ at $4{ }^{\circ} \mathrm{C}$. Brains were then cut into serial coronal sections $(60 \mu \mathrm{m}$ thick) on a vibratome. The sections were kept at $-20{ }^{\circ} \mathrm{C}$ in the antifreeze solution until further processing. Perfused or angiographic brain (i.e., without transcardial perfused fixation) sections were treated with $0.3 \%$ triton X-100 for 10 min and blocked with $10 \%$ normal goat serum or $10 \%$ BSA for 60 min at room temperature. Then, samples were incubated with primary antibody diluted in blocking solution overnight at $4{ }^{\circ} \mathrm{C}$. We used the following primary antibodies: beta amyloid 17-24 (4G8) monoclonal antibody (Covance; Cat\# SIG-39220; 1:100), rat anti-mouse CD31 (BD BioScience; Cat\#553370; 1:50), anti-GluT1 $(\sim 54 \quad \mathrm{kDa})$ rabbit polyclonal antibody (Millipore; Cat\#07-1401; 1:100), rabbit anti-mouse fibrinogen/fibrin polyclonal antibody (MyBioSource; MBS315814; 1:700), mouse anti-GFAP (Sigma, G3893; 1:1000), rabbit anti-SMA (ABCAM, ab5694; 1:100), rabbit anti-Iba-1 (WAKO, \#019-19741; 1:500), Anti-phospho-IGF-IR $\beta$ (Tyr1135/1136)/insulin receptor (IR)- $\beta$ (Tyr1150/1151) (19H7) and anti-IR $\beta$ (Cell Signaling Technology \#3024 and \#3025), anti-P-Akt (Thr 473) and anti-Akt (Cell Signaling Technology, \#9271 and \#9272), mouse antiGSK3 $\beta$ (Ser9) (Cell Signaling Technology \#9336) and anti-GSK-3 $\beta$ (\#9315), Tau-5 (Santa Cruz, sc-58860) and goat anti-mouse IgG (Biolegend; Cat\# 40531;). Thioflavine $\mathrm{S}$ was obtained from Sigma. Sections were washed in PBS and incubated with the following secondary antibodies dilated in blocking solution $60 \mathrm{~min}$ at room temperature: Alexa Fluor 594 goat anti-mouse IgG $(\mathrm{H}+\mathrm{L})$ (Invitrogen; A11032; 1:500) to detect mouse $\mathrm{A} \beta$, Alexa Fluor 488 or 555 goat anti-rat (Invitrogen; A1106 and A11057, respectively) 1:500 to detect mouse CD31, Alexa Fluor 594 goat anti-rabbit $\operatorname{IgG}(\mathrm{H}+\mathrm{L})$ (Invitrogen; A11037; 1:500) to detect GluT1 and fibrinogen, and DyLight 488-conjugated AffiniPure donkey anti-goat IgG $(\mathrm{H}+\mathrm{L})$ (Jackson ImmunoResearch; 
Code 705-485-147; 1:500) to detect mouse IgG. Sections were washed in PBS and counterstained with DAPI (Roche Diagnostics, Lot \# 70237122, 1:1000). After washing with PBS three times, sections were mounted on microscopy slides and covered with Fluoromount-G (SouthernBiotech, Cat \# 0100-01).

\section{Western blot analysis and quantitative real-time RT-PCR (qRT-PCR)}

Western blot analysis was performed as described [10, 12] using $20 \mu \mathrm{g}$ of total protein lysates freshly prepared from the frontal brain tissue. For qRT-PCR, RNA was prepared using TRIzol (Invitrogen) according to the manufacturer's instructions. Single-stranded cDNA was synthesized from $1 \mu \mathrm{g}$ of total RNA using High Capacity cDNA Reverse Transcription kits (Applied Biosystems). Quantitative realtime PCR was performed with RealMasterMix SYBR ROX (5 Prime) according to the manufacturer's protocols using the same rat and mouse GAPDH primers. Primers for other mouse genes are listed below: Mmp2 taacctggatgccgtcgt/ttcaggtaataagcacccttgaa; Vegfa gttgcctagtgggtg gatct/gctacccatccagcctgtt; fgf2 cggctctactgcaagaacg/ tgctt ggagttgtagtttgacg; agcttcaggcaggcagtatc/Il1b gtcacagaggatg ggctctt; tnfa ccctcacactcagatcatcttct/gctacgacgtgggctacag; gfap tcgagatcgccacctacag/gtctgtacaggaatggtgatgc; TGF1b tggagcaacatgtggaactc/ gtcagcagccggttacca; Ager agcctggga aggaagcac/ggctgtgatgttctgaccac; abcb1b ccaaattctacatcttgg ctgac/ttcaaactccatcaccacctc; rest agcaacaaagaaaaggagttgg/ acctgggtggccataactg.

\section{Assessment of cerebral microvessel structure and function}

Cerebral blood vessel density was assessed according to the point-counting method [57] on FITC-dextran-perfused sections that were counterstained with DAPI. The number of point intersections of CD31-positive and FITC-dextranperfused profiles was scored in a 100-point grid, which covered the entire surface of the microscopic field so that surface area was calculated according to the magnification used $(\times 100)$. Vessel density is expressed as the percentage of brain surface cover with vessels. Measurements were performed in bilateral CA1 regions including oriens layer, pyramidal cell layer and radiatum layer hippocampi in 4 sections taken at $0.6 \mathrm{~mm}$ intervals $(9-10$ sections per brain with 4 sections showing both CA1 region and cerebral neocortex, ranging from Bregma 1.98 to Bregma $-3.28 \mathrm{~mm}$ ). To calculate the number of cerebral infarctions, 9-10 angiographic sections taken at $0.6 \mathrm{~mm}$ intervals (ranging from Bregma 1.98 to Bregma $-3.28 \mathrm{~mm}$ ) were assessed using fluorescence microscopy under low magnification (10x), with results being expressed as arbitrary units (total number of infarctions in 9-10 brain sections). CAA and vascular smooth muscle cell injury were determined using $C D 31$ in combination with $A \beta$ and SMA immunofluorescent staining, respectively. The percentage of $A \beta$ positive arterioles in bilateral hippocampal fissures were calculated in 4 hippocampal sections taken at $0.6 \mathrm{~mm}$ intervals $(9-10$ sections per brain ranging from Bregma 1.98 to Bregma $-3.28 \mathrm{~mm}$ with 4 sections showing hippocampus). Blood-brain barrier breakdown was evaluated by either extravasations of mouse IgG by using immunofluorescent stain or deposition of ferric iron from hemorrhage by using Perl's Prussian blue staining.

\section{Statistical analysis}

Statistical analyses were performed using unpaired twotailed or one-tailed Student's $t$-test. Data are reported as mean \pm S.E.M. Statistical significance was set at $P<0.05$.

\section{Additional file}

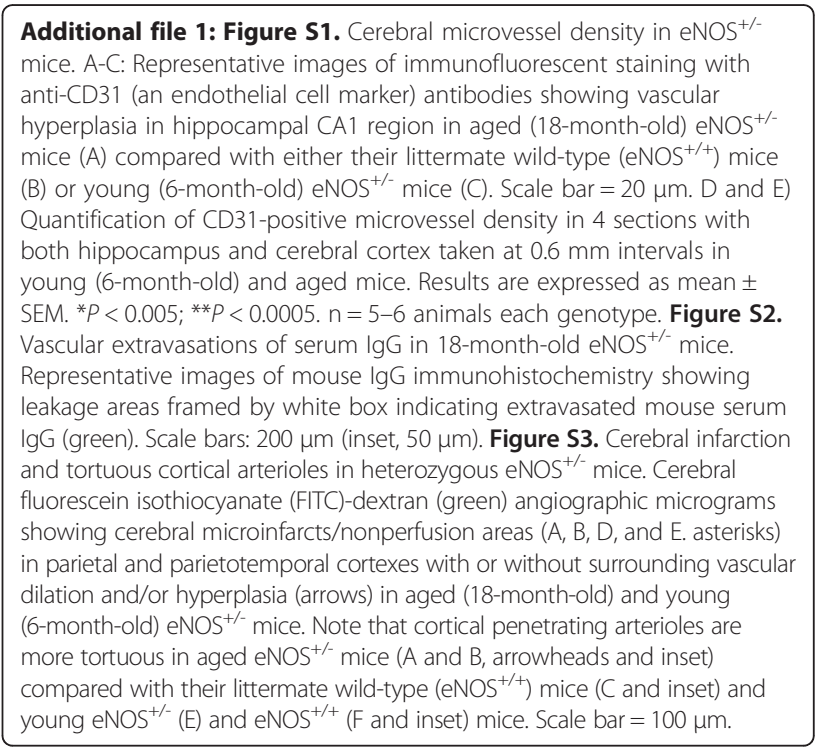

\section{Abbreviations}

eNOS: Endothelial nitric oxide synthase; CAA: Cerebral amyloid angiography; FAD: Familial Alzheimer's disease; SAD: Sporadic Alzheimer's disease; CBF: Cerebral blood flow; GluT1: Glucose Transporter-1.

\section{Competing interests}

The authors declare that they have no competing interests.

\section{Authors' contributions}

$X-L T, M P M, K U M, A D$, and FFL designed research and analyzed data; X-LT, $Y-Q X, X-F W, J-J L$, and $L-B L$ performed experiments; $X-L T$, and FFL wrote the paper. All authors have read and approved the final manuscript.

\section{Acknowledgments}

We thank Profs. Aviv Hassid, Thaddeus S. Nowak Jr., William A. Muller and Dr. Chun Cai for helpful discussions. This work was supported by NIH grants R01 AG031893 (to F.F.L.), R01AG031253 and R01AG040230 (to M. P. M.), R21 AG041934 (to F.F.L. and M.P.M.), R21 NS083908 (to F.F.L.), R01 HL104631 and R37 AA11560 (to A.M.D.), and RO1HLO79109 (to K.U.M.) and by Alzheimer Association grant IIRG-11-204040 (to F.F.L.).

\section{Author details}

'Departments of Pharmacology, University of Tennessee Health Science Center, 874 Union Avenue/Crowe 401, Memphis, TN 38163, USA. ${ }^{2}$ Neurology \& Neurobiology, University of Tennessee Health Science Center, 874 Union 
Avenue/Crowe 401, Memphis, TN 38163, USA. ${ }^{3}$ Anatomy \& Neurobiology, University of Tennessee Health Science Center, 874 Union Avenue/Crowe 401, Memphis, TN 38163, USA. ${ }^{4}$ Department of Neurology, Wuxi Second People Hospital of Nanjing Medical University, 68 Zhongshan Road, Wuxi, Jiangsu province 214002, PR China. ${ }^{5}$ Department of Cardiology, The First Affiliated Hospital, Zhengzhou University, No.1 Jianshe road, Zhengzhou, Henan province 450052, PR China.

Received: 9 March 2015 Accepted: 27 May 2015

Published online: 24 June 2015

\section{References}

1. Dai X, Faber JE. Endothelial nitric oxide synthase deficiency causes collateral vessel rarefaction and impairs activation of a cell cycle gene network during arteriogenesis. Circ Res. 2010;106:1870-81.

2. Liu Y, Lu X, Xiang FL, Poelmann RE, Groot ACG, Robbins J, et al. Nitric oxide synthase-3 deficiency results in hypoplastic coronary arteries and postnatal myocardial infarction. Eur Heart J. 2014;35:920-31.

3. Cui X, Chopp M, Zacharek A, Zhang C, Roberts C, Chen J. Role of endothelial nitric oxide synthase in arteriogenesis after stroke in mice. Neuroscience. 2009;159:744-50.

4. Baumbach GL, Sigmund CD, Faraci FM. Structure of cerebral arterioles in mice deficient in expression of the gene for endothelial nitric oxide synthase. Circ Res. 2004;95:822-9.

5. Freedman JE, Sauter R, Battinelli EM, Ault K, Knowles C, Huang PL, et al. Deficient platelet-derived nitric oxide and enhanced hemostasis in mice lacking the NOSIII gene. Circ Res. 1999;84:1416-21.

6. Kuhlencordt PJ, Gyurko R, Han F, Scherrer-Crosbie M, Aretz TH, Hajjar R, et al. Accelerated atherosclerosis, aortic aneurysm formation, and ischemic heart disease in apolipoprotein $\mathrm{E} /$ endothelial nitric oxide synthase double-knockout mice. Circulation. 2001;104:448-554.

7. Freedman JE, Loscalzo J. Nitric oxide and its relationship to thrombotic disorders. J Thromb Haemost. 2003;1:1183-8. Review.

8. Nakayama T, Sato W, Yoshimura A, Zhang L, Kosugi T, Campbell-Thompson $M$, et al. Endothelial von Willebrand factor release due to eNOS deficiency predisposes to thrombotic microangiopathy in mouse aging kidney. Am J Pathol. 2010;176:2198-208.

9. Austin SA, Santhanam AV, Katusic ZS. Endothelial nitric oxide modulates expression and processing of amyloid precursor protein. Circ Res. 2010;107:1498-502.

10. Kwak YD, Wang R, Li JJ, Zhang YW, Xu H, Liao FF. Differential regulation of BACE1 expression by oxidative and nitrosative signals. Mol Neurodegener. 2011:6:17.

11. Austin SA, Santhanam AV, Hinton DJ, Choi DS, Katusic ZS. Endothelial nitric oxide deficiency promotes Alzheimer's disease pathology. J Neurochem. 2013;127:691-700.

12. Wang R, Li JJ, Diao S, Kwak YD, Liu L, Zhi L, et al. Metabolic stress modulates Alzheimer's $\beta$-secretase gene transcription via SIRT1-PPARY-PGC-1 in neurons. Cell Metab. 2013;17:685-94.

13. Fatini C, Sofi F, Gensini F, Sticchi E, Lari B, Pratesi G, et al. Influence of eNOS gene polymorphisms on carotid atherosclerosis. Eur J Vasc Endovasc Surg. 2004:27:540-4

14. Hassan A, Gormley K, O'Sullivan M, Knight J, Sham P, Vallance P, et al. Endothelial nitric oxide gene haplotypes and risk of cerebral small-vessel disease. Stroke. 2004;35:654-9.

15. Song J, Kim OJ, Kim HS, Bae SJ, Hong SP, Oh D, et al. Endothelial nitric oxide synthase gene polymorphisms and the risk of silent brain infarction. Int J Mol Med. 2010;25:819-23.

16. Casas JP, Bautista LE, Humphries SE, Hingorani AD. Endothelial nitric oxide synthase genotype and ischemic heart disease: meta-analysis of 26 studies involving 23028 subjects. Circulation. 2004;109:1359-65.

17. Ferlazzo N, Gorgone G, Caccamo D, Currò M, Condello S, Pisani F, et al. The 894G > T (Glu298Asp) variant in the endothelial NOS gene and MTHFR polymorphisms influence homocysteine levels in patients with cognitive decline. Neuromol Med. 2011:13:167-74.

18. Noiri E, Satoh H, Taguchi J, Brodsky SV, Nakao A, Ogawa Y, et al. Association of eNOS Glu298Asp polymorphism with end-stage renal disease. Hypertension. 2002:40:535-40.

19. Leeson CP, Hingorani AD, Mullen MJ, Jeerooburkhan N, Kattenhorn M, Cole TJ, et al. Glu298Asp endothelial nitric oxide synthase gene polymorphism interacts with environmental and dietary factors to influence endothelial function. Circ Res. 2002:90:1153-8.

20. Jeynes B, Provias J. Significant negative correlations between capillary expressed eNOS and Alzheimer lesion burden. Neurosci Lett. 2009;463:244-8.

21. Atochin DN, Huang PL. Endothelial nitric oxide synthase transgenic models of endothelial dysfunction. Pflugers Arch. 2010;460:965-74.

22. Shesely EG, Maeda N, Kim HS, Desai KM, Krege JH, Laubach VE, et al. Elevated blood pressures in mice lacking endothelial nitric oxide synthase. Proc Natl Acad Sci U S A. 1996:93:13176-81.

23. Zlokovic BV. Neurovascular pathways to neurodegeneration in Alzheimer's disease and other disorder. Nat Rev Neurosci. 2011;12:723-38.

24. ladecola C. The pathobiology of vascular dementia. Neuron. 2013;80:844-65.

25. Dickstein DL, Walsh J, Brautigam H, Stockton Jr SD, Gandy S, Hof PR. Role of vascular risk factors and vascular dysfunction in Alzheimer's disease. Mt Sinai J Med. 2010;77:82-102.

26. Grammas P, Martinez J, Sanchez A, Yin X, Riley J, Gay D, et al. A new paradigm for the treatment of Alzheimer's disease: targeting vascular activation. J Alzheimers Dis. 2014:40:619-30.

27. Smith EE, Schneider JA, Wardlaw JM, Greenberg SM. Cerebral microinfarcts: the invisible lesions. Lancet Neurol. 2012:11:272-82.

28. Shih AY, Blinder P, Tsai PS, Friedman B, Stanley G, Lyden PD, et al. The smallest stroke: occlusion of one penetrating vessel leads to infarction and a cognitive deficit. Nat Neurosci. 2013;16:55-63.

29. Deane R, Wu Z, Zlokovic BV. RAGE (yin) versus LRP (yang) balance regulates alzheimer amyloid beta-peptide clearance through transport across the blood-brain barrier. Stroke. 2004;35(11 Suppl 1):2628-31.

30. Jeynes B, Provias J. Evidence for altered LRP/RAGE expression in Alzheimer lesion pathogenesis. Curr Alzheimer Res. 2008;5:432-43.

31. Yan SD, Bierhaus A, Nawroth PP, Stern DM. RAGE and Alzheimer's disease: a progression factor for amyloid-beta-induced cellular perturbation? J Alzheimers Dis. 2009;16:833-43.

32. Kanekiyo T, Liu C-C, Shinohara M, Li J, Bu G. LRP1 is brain vascular smooth muscle cells mediates local clearance of Alzheimer's amyloid - $\beta$. J Neurosci. 2012;32:16458-65.

33. Tesseur I, Wyss-Coray T. A role for TGF-beta signaling in neurodegeneration: evidence from genetically engineered models. Curr Alzheimer Res. 2006;3:505-13.

34. Luckhaus C, Flüb MO, Wittsack HJ, Grass-Kapanke B, Jänner M, Khalili-Amiri $R$, et al. Detection of changed regional cerebral blood flow in mild cognitive impairment and early Alzheimer's dementia by perfusion-weighted magnetic resonance imaging. Neuroimage. 2008;40:495-503.

35. Schuff N, Matsumoto S, Kmiecik J, Studholme C, Du A, Ezekiel F, et al. Cerebral blood flow in ischemic vascular dementia and Alzheimer's disease, measured by arterial spin-labeling magnetic resonance imaging. Alzheimers Dement. 2009:5:454-6.

36. Hu WT, Wang Z, Lee VM, Trojanowski JQ, Detre JA, Grossman M. Distinct cerebral perfusion patterns in FTLD and AD. Neurology. 2010;75:881-8.

37. Moore C, Tymvios C, Emerson M. Functional regulation of vascular and platelet activity during thrombosis by nitric oxide and endothelial nitric oxide synthase. Thromb Haemost. 2010;104:342-9.

38. Garcia-Alloza M, Gregory J, Kuchibhotla KV, Fine S, Wei Y, Ayata C, et al. Cerebrovascular lesions induce transient $\beta$-amyloid deposition. Brain 2011;134:3697-707.

39. Chesnutt JK, Han HC. Tortuosity triggers platelet activation and thrombus formation in microvessels. J Biomech Eng. 2011;133:121004.

40. Faraci FM, Sigmund CD, Shesely EG, Maeda N, Heistad DD. Responses of carotid artery in mice deficient in expression of the gene for endothelial NO synthase. Am J Physiol. 1998:274:H564-70.

41. Lamping KG, Nuno DW, Shesely EG, Maeda N, Faraci FM. Vasodilator mechanisms in the coronary circulation of endothelial nitric oxide synthase-deficient mice. Am J Physiol Heart Circ Physiol. 2000;279:H1906-12.

42. Feng $Q$, Song W, Lu X, Hamilton JA, Lei M, Peng T, et al. Development of heart failure and congenital septal defects in mice lacking endothelial nitric oxide synthase. Circulation. 2002;106:873-9.

43. Balasubramaniam V, Tang JR, Maxey A, Plopper CG, Abman SH. Mild hypoxia impairs alveolarization in the endothelial nitric oxide synthasedeficient mouse. Am J Physiol Lung Cell Mol Physiol. 2003;284:L964-71.

44. Wang CH, Li F, Hiller S, Kim HS, Maeda N, Smithies O, et al. A modest decrease in endothelial NOS in mice comparable to that associated with human NOS3 variants exacerbates diabetic nephropathy. Proc Natl Acad Sci U S A. 2011:108:2070-5. 
45. Fagan KA, Fouty BW, Tyler RC, Morris Jr KG, Hepler LK, Sato K, et al. The pulmonary circulation of homozygous or heterozygous eNOS-null mice is hyperresponsive to mild hypoxia. J Clin Invest. 1999;103:291-9.

46. Li H, Guo Q, Inoue T, Polito VA, Tabuchi K, Hammer RE, et al. Vascular and parenchymal amyloid pathology in an Alzheimer disease knock-in mouse model: interplay with cerebral blood flow. Mol Neurodegener. 2014;9:28.

47. Thomason LAM, Stefanovic B, McLaurin J. Cerebrovascular contribution to Alzheimer's disease pathophysiology and potential therapeutic interventions in mouse models. Euro J Neurosci. 2013;37:1994-2000.

48. Gilbert JJ, Vinters HV. Cerebral amyloid angiopathy: incidence and complications in the aging brain. I Cerebral Hemorrhage Stroke. 1983;14:915-23.

49. Vinters HV, Gilbert JJ. Cerebral amyloid angiopathy: incidence and complications in the aging brain. II. The distribution of amyloid vascular changes. Stroke. 1983;14:924-8.

50. Soontornniyomkij V, Lynch MD, Mermash S, Pomakian J, Badkoobehi H, Clare R, et al. Cerebral microinfarcts associated with severe cerebral beta-amyloid angiopathy. Brain Pathol. 2010;20:459-67.

51. Kraff PR, Bailey EL, Lekic T, Rolland WB, Altay O, Tang J, et al. Etiology of stroke and choice of models. Int J Stroke. 2012;7:398-406.

52. Jeffs B, Clark JS, Anderson NH, Gratton J, Brosnan MJ, Gauguier D, et al. Sensitivity to cerebral ischemic insult in a rat model of stroke is determined by a single genetic locus. Nat Genet. 1997;16:364-7.

53. Bailey EL, McCulloch J, Sudlow C, Wardlaw JM. Potential animal models of lacunar stroke: a systematic review. Stroke. 2009;40:e451-8.

54. Zhang X, Zheng X, Jiang F, Zhang ZG, Katakowski M, Chopp M. Dual-color fluorescence imaging in a nude mouse orthotopic glioma model. J Neurosci Methods. 2009;181:178-85.

55. Jennings $B L$, Estes AM, Anderson LJ, Fang XR, Yaghini FA, Fan Z, et al. Cytochrome P450 1B1 gene disruption minimizes deoxycorticosterone acetate-salt-induced hypertension and associated cardiac dysfunction and renal damage in mice. Hypertension. 2012;60:1510-6.

56. Dhanushkodi A, McDonald MP. Intracranial v. cholerae sialidase protects against excitotoxic neurodegeneration. PLoS One. 2011;6:e29285.

57. Lopez-Lopez C, LeRoith D, Torres-Aleman I. Insulin-like growth factor I is required for vessel remodeling in the adult brain. Proc Natl Acad Sci U S A 2004; 101:9833-8.

\section{Submit your next manuscript to BioMed Central and take full advantage of:}

- Convenient online submission

- Thorough peer review

- No space constraints or color figure charges

- Immediate publication on acceptance

- Inclusion in PubMed, CAS, Scopus and Google Scholar

- Research which is freely available for redistribution 